\title{
Application of Value Engineering in Head Stack Assembly Process: A Case Study
}

\author{
P. Pimpanont and P. Chutima
}

\begin{abstract}
Demand for data storage devices such as hard disk is rapidly increasing as almost every aspect of modern life has been digitized. Presently, one of the main challenges for storage manufacturers is to reduce operational cost while increasing the customer satisfaction so that the company can survive in the fierce competition. Recognizing the necessity of continuous functional improvement, this paper has adopted a Value Engineering (VE)-based methodology for product cost reduction in the manufacturing process of hard disk components. Value Engineering has been recognized as a powerful technique to achieve value enhancement and cost reduction. Toward this, the 7-phase work plans were developed within the framework of the VE methodology. This proposed approach has been implemented and validated in a case study, which focused on head stack assembly (has) process to reduce cost and improve quality. Application results showed that the indirect materials product cost significantly decreased by $30 \%$ while the targets of main functionalities have been achieved.
\end{abstract}

Index Terms - Value engineering, head stack assembly, cost reduction.

\section{INTRODUCTION}

In recent years, storage products have been in high demand to support the rapid growth of data which has been driven up, by social media, enterprise applications and cloud computing. Especially, the Hard Disk Drive (HDD) plays an increasingly important role due to its economic efficiency per gigabyte over other storage products. The capacity requirement is continuously increasing, whereas the size of HDD needs to be maintained or reduced. Consequently, the hard disk and its components have been designed to increase both quality and reliability, which are the key characteristics to HDD's performance.

Presently, the hard disk drive manufacturers are focusing on the reliability of vibration in each component of HDD. If forced vibration is equal to the natural frequency, the amplitude of vibration increases significantly. This phenomenon is known as resonance, which presents a significant problem in HDD manufacturing, especially for Head Stack Assembly (HSA), which is one of the core components of a HDD. It comprises Actuator Arm and Head Gimbal Assembly (HGA), which is the assembly of the slider and the suspension, as shown in Fig. 1.

The resonant mode can cause serious problems for

Manuscript received January 11, 2015; revised June 9, 2015.

P. Pimpanont is with the Department of Industrial Engineering, Chulalongkorn University, Bangkok, Thailand (e-mail: aom_pimpanont@hotmail.com).

P. Chutima is with the Industrial Engineering Department, Chulalongkorn University, Bangkok, Thailand. He is also with the Regional Centre of Manufacturing System Engineering, Chulalongkorn University, Thailand (e-mail: cparames@chula.ac.th). positioning accuracy in head-positioning systems of hard disk drives. It could also lead to the reliability problem that cause read-write errors, and durability problems of media's surface damage, which affects the efficiency of the hard disk drive [1]. To control the resonance in HSA, various parameters are controlled stringently, in the additional manufacturing process. However, these processes will also make manufacturing cost increase significantly.

To reach the target-cost by maintaining the necessary function and quality required, a methodology based on the technique of Value Engineering (VE) is proposed here. VE is proposed to employ in this case study due to its advantage in terms of Functional Analysis and Cost Focus. The main purpose of this paper is to find out the way to reduce the cost of indirect material applied in HSA resonance reduction process, called "Tail Fixing Process" through functional analysis, functional evaluation, then puts forward proposals to the improvement of this process, and finally evaluates the improving program.

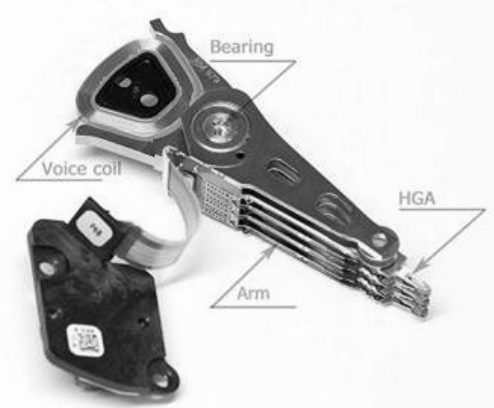

Fig. 1. Head stack assembly.

\section{LITERATURE REVIEW}

Competing in a Global market the pace of change is quickening, manufacturers and businesses are forced to increase the value of their products/services and to reduce unnecessary costs [2].

Value engineering is based on a methodology developed by Lawrence Miles, who worked for the General Electric in the USA during the late 1940s (post war). Value Engineering began with a creative team-based approach which then allowed many alternatives to the existing solution. Soon after Miles developed this systematic methodology, his concepts were recognized as a powerful approach to problem solving through function-based techniques. Later in the 20th century, value engineering started to spread cross the world and has been applied to many different industries such as healthcare and government services.

Basically, VE is a well-structured way of evaluating a 
system or a process through the functional approach. VE is designed to eliminate or modify any element that significantly contributes to the overall cost reduction together with a sustained or enhanced value of overall function [3].

Arthur E. Mudge is the first one to introduce a 7-phase of VE Job plan throughout company's value and cost reduction program, which comprises of information, function, creative, evaluation, investigation and recommendation phases [4]. Each phase of the VE Job Plan requires creative behavior which involves the change. The more analytical steps in the value methodology, the phases typically performed in a project setting involving all stakeholders in order to develop the maximum number of alternatives to achieve the product or service's required functions. Systematic pursuit of the methodologies within these phases leads to recommendations for improving the existing situation and thereby increasing value [3].

Numerous opportunities exist for VE to offer substantial benefits to businesses, such as eliminating high-cost drivers, improving performance, reliability, or resolving interesting issues. The studies of Value Engineering are presented below.

There is a case study conducted by Liu and Zhao [5] on a selection of air-conditioning system for a three-storey villa. Application case shows it is suitable to select the scheme for by using VE method. Annappa and Panditrao [6] perform a case study at a Furniture manufacturing in India in which the material size of the product is proposed to change according to the VE methodology, the proper material is chosen such that the cost is reduced without affecting the value of the product and its design. Li and Zheng [7] find out the improved order of the headstock gear through VE analysis which functional, cost and vale coefficient is calculated using VE method, they then put forward proposals for the improvement of lower cover and screw stem. Viboonsirisayveekul [8] applied VE in wiring harness industry, the result is revealed that VE is able to help factory to achieve the cost reduction target as well as increase customer satisfaction in the aspect of price. Dong and Jie [9] proposed VE as a useful tool for evaluating residential for consumers and real estate developers by connect the residential function with the cost.VE also capability to increase construction industry competitiveness by driven the benefit provided to a construction project. Berawi et al. [10] employed VE concept in Mega infrastructures project development, the results identified additional function and life cycle cost analysis confirmed the increasing in value for money from additional functions in particular projects. Atabay and Galipogullari [11] explained the application of $\mathrm{VE}$ in construction project by covering Motorway construction as the sample project, the satisfactory results shown money and time were saved in total.

The evaluation model that established in the light of VE theory doesn't only involve the economic factors but also take other factors which related to project, thereby result is given more comprehensively [12].

This comprehensive review of the literature has summarized the benefit of VE as an effective and powerful methodology for functional analysis and cost reduction for any manufacturing process and service industry. However, there are no specific researches to elaborate the questions of benefit distribution that HDD manufacturing earned by using VE. Consequently, VE methodology is selected to apply in the case study to illustrate its benefit. As one of the elements of a well-designed storage solution is to reduce cost, whereas its functionality, reliability and storage capacity are maintained or enhanced.

\section{CASE STUDY}

A case study was conducted in the world's leading manufacturer of hard disk drives and storage solutions. The name of the company is non-disclosure due to its confidentiality and commercial reasons. This study focused on the tail fixing process which is applied to HSA to reduce the off-track due to a resonance frequency. In this process the qualified adhesive will be applied to HSA unit at a reference position to adhere HGA tail with actuator Arm. Then ultraviolet light curing is applied to dry up the adhesive and form the bonds.

Adhesive is the principle direct material used in the tail fixing process. The latest 3 years company's financial reports, shown in Fig. 2, show the adhesive had the highest proportion of total indirect material spending and is continually increasing year on year.

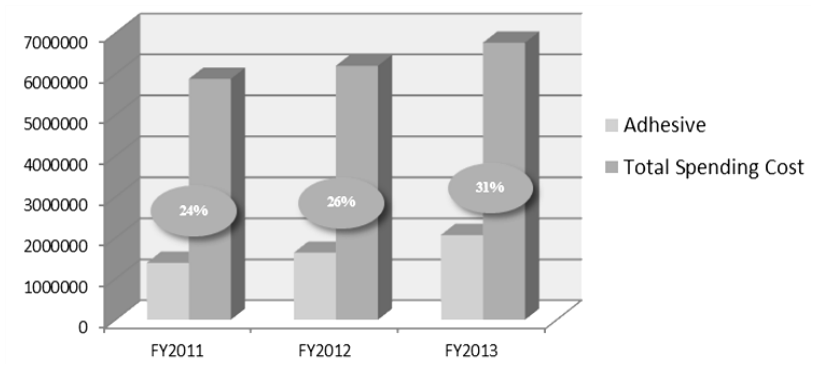

Fig. 2. A comparison of adhesive expense versus total indirect material cost expense.

The team decided to adopt the Value engineering approach in order to reduce an indirect material cost which occurred in the tail fixing process. The formal procedural model of VE process is called a VE Job plan. The seventh phase of a job plan in Fig. 3, presented by Arthur E. Mudge [4] is the well-known approach. The following section describes and illustrates that using the value engineering approach was used to reduce the cost of indirect materials in tail fixing process in the company.

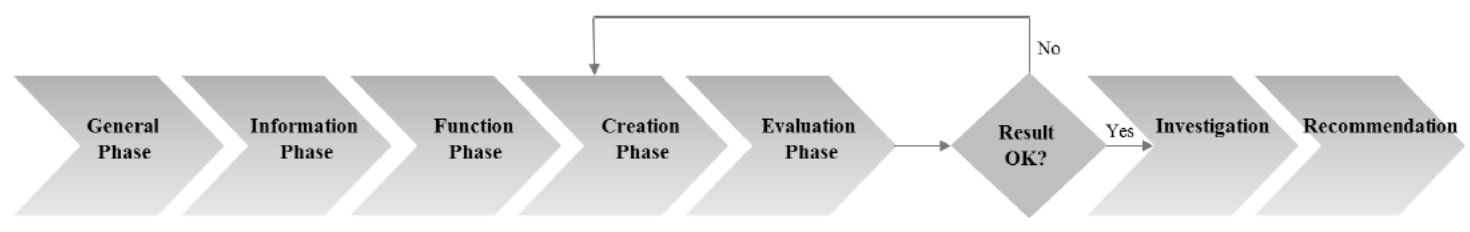

Fig. 3. Seven phases VE job plan by Arthur E. Mudge. 
Phase 1: General phase - The purpose of this phase is to prepare for the value study. In order to respond to value engineering approach, any business that uses VE need to establish a team of employees that represent areas in which incremental costs arise. As shown in Fig. 4, the development VE team is the cross - functional team, the team members are selected from people that have an impact on the costs and quality of the product. The representatives involved in a VE team include: Development engineer, Industrial Engineer, Process engineer, Buyer, Finance including team supporting. VE leader is a professional engineer who is certified value specialists and leads for doing VE job. The success of any VE is related to the qualities of VE team.

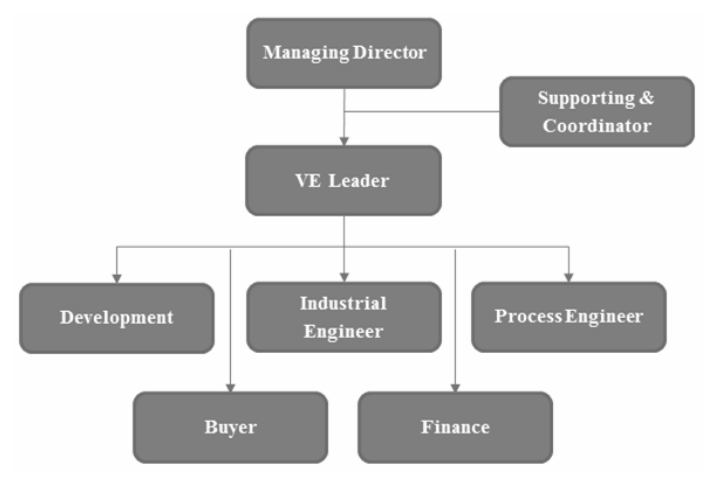

Fig. 4. The VE team.

Phase 2: Information phase - During this phase, the VE team gathers all possible information consistent with the study through the questions what, where, when, why, who, how and how much $(5 \mathrm{~W} 2 \mathrm{H})$. The individuals examine and collect data, in the context of tail fixing process it is as follows:

- Finance Department - provides the information about indirect material cost in financial terms.

- Buyer - provides the general information of product (adhesive) including product cost.

- Development Engineer — provides product specification and data in terms of engineering techniques.

- Process Engineer - provides the technical information that relates to tail fixing process e.g. ability for ultraviolet light curing, the rework and removal process.
- Industrial Engineer - does process time study that relates to material or product change.

Phase 3: Function phase - The next stage of the VE is to commence the analysis of the product by identifying systematically the important functions of a product. Functional analysis outlines the basic functions of a product using a verb and a noun. The identified functions are classified as main function, those are necessary to the product and the secondary function, those that subsides the main function. The function of adhesive is analyzed as Table I.

To determine the importance of function we specified the abbreviation of function and its weight as a table shown in Table II. Each function is compared with the others and the relative importance of each one was determined by means of a numeric evaluation supported by the Mudge Diagram [13]. This comparison has the purpose of evaluating how each function relates to the complete system. The evaluated result is shown in Fig. 5.

TABLE I: THE FunCtIONAL ANALYSIS OF ADHESIVE

\begin{tabular}{|c|c|c|c|c|}
\hline \multirow{2}{*}{ Description } & \multicolumn{2}{|c|}{ Function } & \multicolumn{2}{|c|}{ Function } \\
\hline & Verb & Noun & Basic & Secondary \\
\hline Adhesive & $\begin{array}{l}\text { Hold } \\
\text { Control } \\
\text { Reduce } \\
\text { Limit } \\
\text { Support }\end{array}$ & $\begin{array}{l}\text { Parts } \\
\text { Position } \\
\text { Resonance } \\
\text { Movement } \\
\text { Components }\end{array}$ & $\checkmark$ & $\begin{array}{l}\checkmark \\
\checkmark \\
\checkmark \\
\checkmark\end{array}$ \\
\hline
\end{tabular}

TABLE II: THE ABBREVIATION OF FUNCTION AND WEIGHT

\begin{tabular}{ccc|} 
Abbreviation & Function & Weight \\
A & Hold Parts & 3 \\
B & Control Position & 1 \\
C & Reduce Resonance & 10 \\
D & Limit Movement & 6 \\
E & Support components & 0 \\
\hline
\end{tabular}

Phase 4: Creative phase - This is an essential phase where innovation begins. The purpose of the Creative Phase is to create possible alternatives ways to perform the functions selected for study. Thus, alternatives should be generated to provide the function at lower cost and maintain the desired quality. The common technique most company's use for creativity is 'brainstorming'.

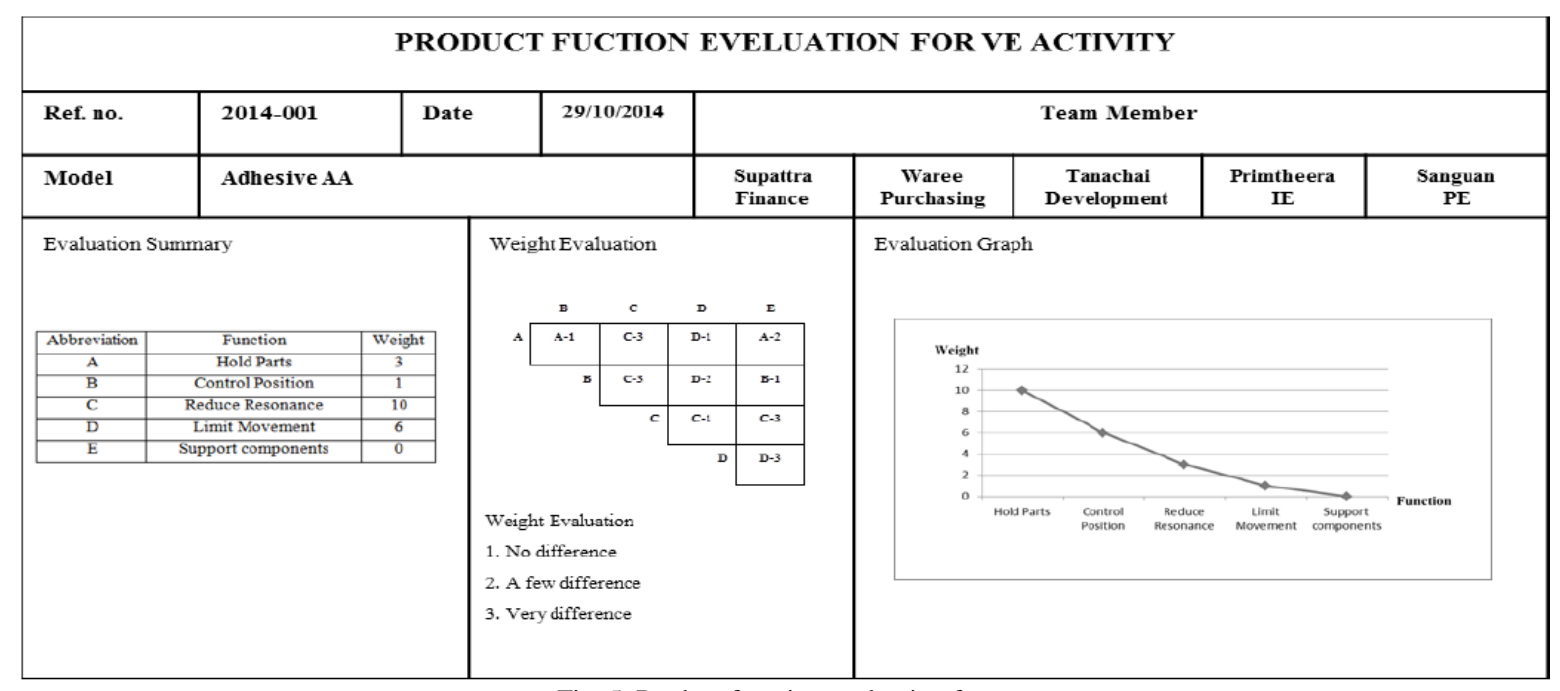

Fig. 5. Product function evaluation form. 
Several alternatives, focused on the functions "Reduce Resonance", are put forward in a series of brainstorming sessions.

At subsequent stage, the proposed ideas will be selected in terms of their technical and economic potential. Listed below are the alternatives obtained during a brainstorming session.

- Idea 1: Change Adhesive Type, Sourcing for new adhesive which provides the lesser cost.

- Idea 2: Ribbed Narrow TGA design, Narrow and Ribbed FOS and eliminate tail fixing. Apply to TGA design either Narrow or Ribbed concept to products.

- Idea 3: Damper new design, Design New Dampers to be bigger which will reduce actuator arm' s motional.

- Idea 4: Flapper positioning optimization, reinforce the TGA tail by adding flapper in the fitting position.

- Idea 5: Design wider Actuator arm in purpose to cover TGA tail.

Phase 5: Evaluation Phase - The purpose of the Evaluation Phase is to refine and select the feasible ideas for development into specific value improvement recommendations. The Evaluation Phase must thoroughly assess all the alternatives to identify the feasible one for value improvement. However, if none of alternatives performs the required criteria satisfactorily, return to creative phase using the knowledge obtained in this phase and create new alternatives. In terms of technical, overall alternatives which applied on HSA unit have to be tested using Mode of Vibration. The model parameters can be determined from a set of "frequency response function (FRF)" measurements by exciting the structure and measuring its response. FRF measurements can be obtained using a Dynamic Signal Analyzer (DSA) as shown in Fig. 6. Ten Modes of vibration, listed in Table III, are tested at HSA level. If any alternative generates the frequency out of Control Spec Limit, it will be declined. The practicable idea is selected based on an evaluation result is idea 1 , since the frequency of 10 Modes of vibration fell in the rage of specification.

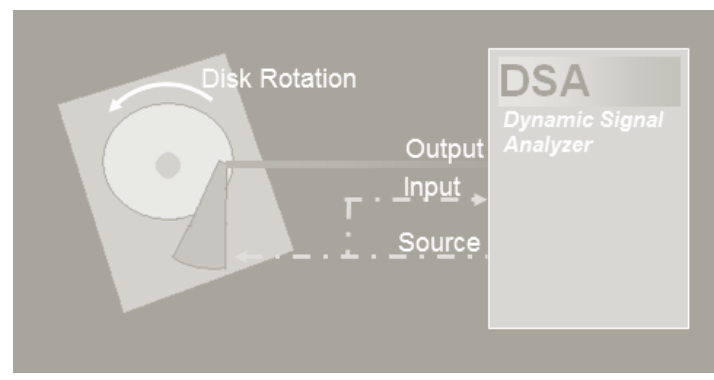

Fig. 6. Dynamic signal analyzer.

Phase 6: Investigation phase - In this phase, the statistical analysis is conducted to validate two of these adhesive types. Twenty-three randomly selected HSA have been applied using each adhesive type. The head off-track percentage is analyzed using Hypothesis testing. In Fig. 7 a number of sample sizes for data collection are calculated by using computer software. To get power of the test at 90 percentages with alpha-error at 5 percentages, 23 HSA units have to be tested for each adhesive type.

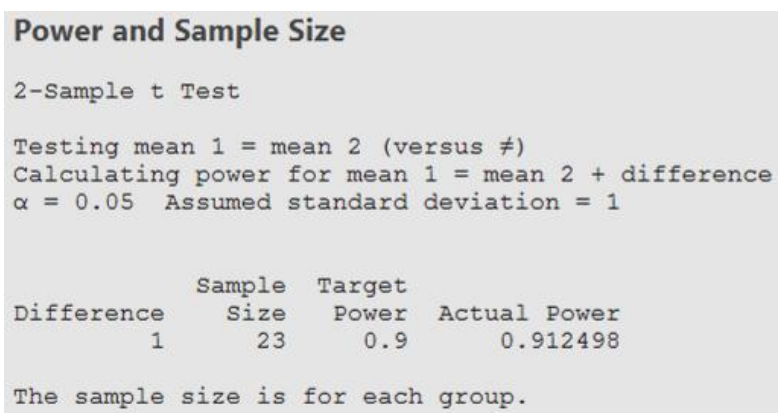

Fig. 7. Power and sample size calculated by minitab17.

The hypothesis statement is the head off-track percentage from a new adhesive type is the same as the old adhesive type. The two-sample $t$-test procedure applied to this study, the result is shown in Fig. 8 . Noticed that the $P$-value is reported to be $P=0.192$, implying that there is no difference between means of the head off-track percentage from which the two adhesive types were applied.

TABLE III: MODE OF HSA VIBRATION AND SPECIFICATION

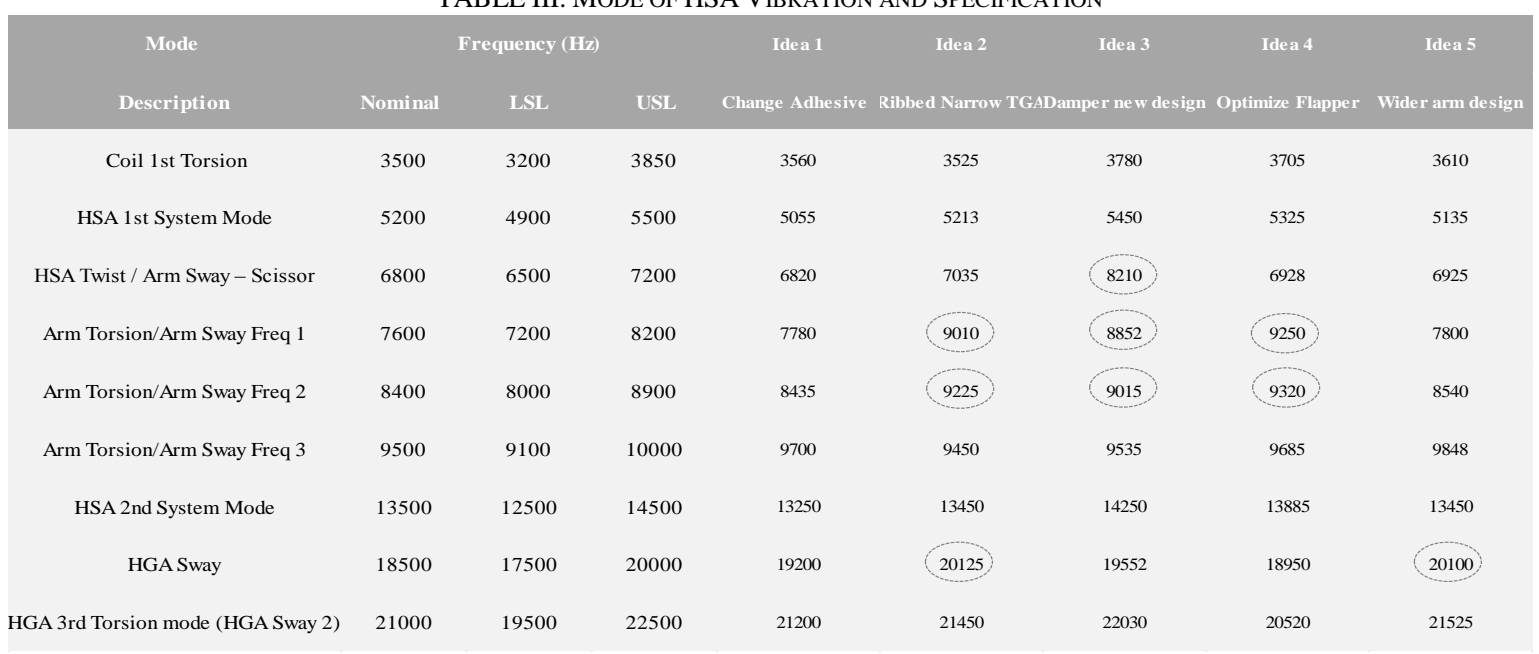

Phase 7: Recommendation phase - The evaluation indicates that the new adhesive type is appropriate to apply in tail fixing process with a $30 \%$ cost reduction. The proposal is put forward to top management and heads of departments for approval, showing the cost of material before and after the value engineering procedure is implemented. 


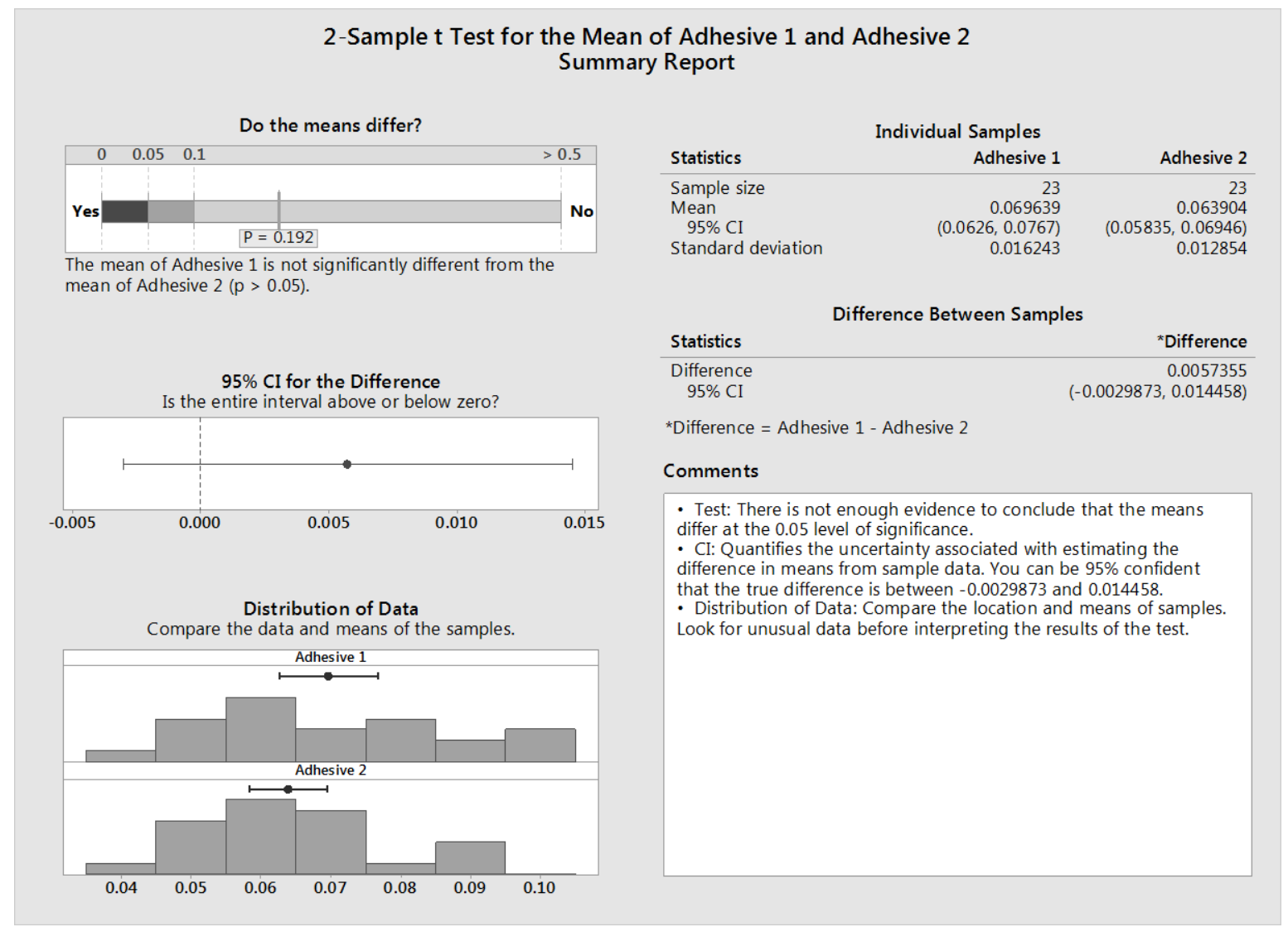

Fig. 8. Two-sample $t$-test output by minitab17.

\section{RESUlTS AND DISCUSSION}

The results indicate through this case study that, it was very helpful to identify the indirect material cost reduction of $30 \%$ in the price of adhesive, applied in the tail fixing process. Meanwhile, the main function of the product "Reduced Resonance", is still maintained. To evaluate the alternatives proposed from VE team, not only is cost involved but also the critical parameter i.e. mode of vibration have to be considered. The statistical analysis and Hypothesis testing are tested to find out which solutions can improve and get the best results. Also, this goal attempts to increase project efficiency and productivity by function analysis and creativity.

The process also has some limitations and disadvantages. Since the method requires several stages, it is dependent on functional interaction of different teams and qualities of creative ideas. Also, there's no monitoring stage, consequently $\mathrm{VE}$ is not paying attention to improving quality continuously. It would be maximally effective and beneficial if VE can be applied at earlier stage of the product life cycle.

\section{CONCLUSION}

This research applies the VE concept to the production of Head Stack Assembly, focusing on tail fixing process. A 7phase VE procedure was implemented to perform cost and functional analysis of specific technical process, in order to achieve costs reduction whilst maintaining performance and quality requirements. The result shows that indirect material cost of product is able to reduce by $30 \%$.

The greatest advantage of VE beyond other improvement techniques is classified into 2 subjects;

- Functional analysis - The disciplined use of functional analysis distinguishes the VE methodology from other problem solving approaches. Functional analysis identifies requirements through questioning the existing system, gathering information, identifying and classifying function. Finally, the innovative and effective solutions will be developed.

- Cost focus - VE only develops alternatives that provide the essential functions. The examination of the cost to worth of each function distinctly displays potential areas for improvement. VE definitely lowers cost and sustains value.

A prosperously implemented methodology may not be the best and appropriate for every problem. Depending on the circumstances, integrating multiple approaches should be able to generate more valuable ideas and expands the benefits of using the approaches independently. For the further study, the synergy of VE and others improvement methodology i.e. Lean, Six Sigma is recommended, to perform a better result and overcome the limitation of each tool.

\section{REFERENCES}

[1] K. Achawakorn, T. Jearsiripongkul1, S. Suksawat1, and K Fanchaeng, "The effect of pivot bearing assembly process on natural frequency of actuator arm," Journal of Energy and Power Engineering, vol. 7, pp. 301-305, 2013.

[2] F. G. H. Behncke, S. Maisenbachera, and M. Maurera, "Extended model for integrated value engineering," in Proc. Conference on Systems Engineering Research, 2014, pp. 781-787.

[3] J. Mandelbaum and D. L. Reed, "Value engineering handbook," IDA Papers, p. 4114, September 2006.

[4] A. Dell'Isola, Value Engineering: Practical Applications, Wiley, 1997. 
[5] J. Y. Liu and Y. X. Zhao, "Application of value engineering in selection of villa air-conditioning system," in Proc. International Conf. on Information Management, Innovation Management and Industrial Engineering, 2009, pp. 517-520.

[6] C. M. Annappa and K. S. Panditrao, "Optimization of furniture product in furniture industry by using value engineering with function analysis, function evaluation and decision matrix - A case study," International Journal of Application or Innovation in Engineering \& Management, vol. 2, pp. 55-64, March 2013.

[7] Z. Liand and X. Zheng, "Appliance of value engineering on the improvement of headstock gear," International Business Research, vol. 3, pp. 44-49, October 2010

[8] K. Viboonsirisayveekul, "Value engineering/value analysis technique based cost reduction: a case study of wiring harness industry," M.S. thesis, Dept. Industrial Engineering, Chulalongkorn University, Bangkok, Thailand, 1999.

[9] Y. Dongand and G. Jie, "A method for evaluating residential value based on value engineering theory," in Proc. International Conference on Information Management, Innovation Management and Industrial Engineering, 2009, pp. 166-170.

[10] M. A. Berawi, B. Susantono et al., "Enhancing value for money of mega infrastructure projects development using value engineering method," in Proc. International Conference on Health and Social Care Information Systems and Technologies, 2014, pp. 1037-1046.

[11] S. Atabay and N. Galipogullari, "Application of value engineering in construction projects," Journal of Traffic and Transportation Engineering, vol. 1, pp. 39-48, December 2013.

[12] H. Shu, L. Duanmu, C. Zhang, and Y. Zhu, "Study on the decisionmaking of district cooling and heating systems by means of value engineering," Renewable Energy, vol. 35, pp. 1929-1939, 2010.
[13] U. Ibusuki and P. C. Kaminski, "Product development process with focus on value engineering and target-costing: A case study in an automotive company," International Journal of Production Economics, vol. 105, pp. 459-474, 2007.

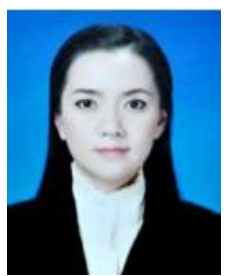

Primtheera Pimpanont graduated in 2007 from Chiang Mai University, with a B.Eng. degree in industrial engineering. Currently she is studying her second year of master program in industrial engineering at Chulalongkorn University. She worked as an industrial engineer with over 7 years of progressive and hands-on experience in electronics and hard disk drive manufacturing. As part of her role, she was involved in an exhaustive program to implement Lean and Six Sigma throughout the company.

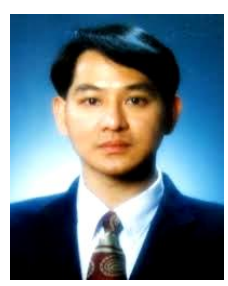

Parames Chutima is a professor in industrial engineering at Chulalongkorn University. $\mathrm{He}$ obtained his B.Eng. degree in electrical engineering from Chulalongkorn University, and the M.Eng. degree in industrial engineering and management from Asian Institute of Technology, and Ph.D. degree in manufacturing engineering and operations management from University of Nottingham. His areas of research include lean, VE and six-sigma implementations in industry. He is now serving as the director of Regional Centre of Manufacturing System Engineering, Faculty of Engineering, Chulalongkorn University. He has published several papers in leading international conferences and journals. 